\title{
Article
}

\section{Effects of single-dose antipurinergic therapy on behavioral and molecular alterations in the valproic acid-induced animal model of autism}

Hirsch, Mauro Mozael, Deckmann, Iohanna, Santos-Terra, Júlio, Staevie, Gabriela Zanotto, Fontes-Dutra, Mellanie, Carello-Collar, Giovanna, Körbes-Rockenbach, Marília, Brum Schwingel, Gustavo, Bauer-Negrini, Guilherme, Rabelo, Bruna, Gonçalves, Maria C B, Corrêa-Velloso, Juliana, Naaldijk, Yahaira, Castillo, Ana R, Schneider, Tomasz, Bambini-Junior, Victorio, Ulrich, Henning and Gottfried, Carmem

Available at http://clok.uclan.ac.uk/31393/

Hirsch, Mauro Mozael, Deckmann, Iohanna, Santos-Terra, Júlio, Staevie, Gabriela Zanotto, Fontes-Dutra, Mellanie, Carello-Collar, Giovanna, KörbesRockenbach, Marília, Brum Schwingel, Gustavo, Bauer-Negrini, Guilherme et al (2020) Effects of single-dose antipurinergic therapy on behavioral and molecular alterations in the valproic acid-induced animal model of autism. Neuropharmacology . p. 107930. ISSN 0028-3908

It is advisable to refer to the publisher's version if you intend to cite from the work. http://dx.doi.org/10.1016/j.neuropharm.2019.107930

For more information about UCLan's research in this area go to http://www.uclan.ac.uk/researchgroups/ and search for < name of research Group>.

For information about Research generally at UCLan please go to http://www.uclan.ac.uk/research/

All outputs in CLoK are protected by Intellectual Property Rights law, including Copyright law. Copyright, IPR and Moral Rights for the works on this site are retained by the individual authors and/or other copyright owners. Terms and conditions for use of this material are defined in the policies page. 


\section{CLoK}

Central Lancashire online Knowledge www.clok.uclan.ac.uk 


\section{Effects of single-dose antipurinergic therapy on behavioral and molecular alterations in the valproic acid-induced animal model of autism}

Mauro Mozael Hirsch ${ }^{1,2,3 *}$, Iohanna Deckmann ${ }^{1,2,3}$, Júlio Santos-Terra1,2,3, Gabriela Zanotto Staevie ${ }^{1,2,3}$, Mellanie Fontes-Dutra ${ }^{1,2,3}$, Giovanna Carello-Collar ${ }^{1,2,3}$, Marília Körbes-Rockenbach ${ }^{1,2,3}$, Gustavo Brum Schwingel ${ }^{1,2,3}$, Guilherme Bauer-Negrini ${ }^{1,2,3}$, Bruna Rabelo ${ }^{1,2,3}$, Maria C.B. Gonçalves ${ }^{4}$, Juliana Corrêa-Velloso ${ }^{4}$, Yahaira Naaldijk ${ }^{4}$, Ana R. Castillo ${ }^{4}$, Tomasz Schneider ${ }^{6}$, Victorio Bambini-Junior ${ }^{1,3,5}$, Henning Ulrich ${ }^{4}$, Carmem Gottfried ${ }^{1,2,3 *}$

1. Translational Research Group in Autism Spectrum Disorders-GETTEA, Universidade Federal do Rio Grande do Sul (UFRGS), Ramiro Barcelos street, 2600, 90035-003, Porto Alegre, RS, Brazil. 2. Department of Biochemistry, Universidade Federal do Rio Grande do Sul (UFRGS), Ramiro Barcelos street, 2600, 90035-003, Porto Alegre, RS, Brazil.

3. National Institute of Science and Technology on Neuroimmunomodulation (INCT-NIM), Brasil avenue, 4365, Manguinhos, 21045-900, Rio de Janeiro, RJ, Brazil.

4. Department of Biochemistry, Institute of Chemistry, Universidade de São Paulo (USP), Professor Lineu Prestes avenue, 748, 05508-000 - Vila Universitária, São Paulo, SP, Brazil

5. School of Pharmacy and Biomedical Sciences, University of Central Lancashire, PR1 2HE, Lancashire, Preston, England, UK.

6. School of Medicine, Pharmacy and Health, Durham University, Durham DH1, UK.

*CORRESPONDING AUTHORS:

MMH (mauromhirsch@gmail.com) and CG (cgottfried@ufrgs.br)

Departamento de Bioquímica, ICBS, Universidade Federal do Rio Grande do Sul, Ramiro Barcelos 2600 - 21111. CEP: 90035-003 Porto Alegre-RS, Brazil.

\section{ABSTRACT}

Autism spectrum disorder (ASD) is characterized by deficits in communication and social interaction, restricted interests, and stereotyped behavior. Environmental factors, such as prenatal exposure to valproic acid (VPA), may contribute to the increased risk of ASD. Since disturbed functioning of the purinergic system has been associated with the onset of ASD and used as a potential therapeutic target for ASD in both clinical and preclinical studies, we analyzed the effects of suramin, a nonselective purinergic antagonist, on behavioral, molecular and immunological in an 
animal model of autism induced by prenatal exposure to VPA. Treatment with suramin (20 mg/Kg, intraperitoneal) restored sociability in the three-chamber apparatus and decreased anxiety measured by elevated plus maze apparatus, but had no impact on decreased reciprocal social interactions or higher nociceptive threshold in VPA rats. Suramin treatment had no impact on VPA-induced upregulation of P2X4 and P2Y2 in hippocampus, and P2X4 in medial prefrontal cortex, but normalized an increased level of interleukin 6 (IL-6). Our results suggest an important role of purinergic modulation in behavioral, molecular, and immunological aberrations described in VPA model, and suggest that purinergic system might be a potential target for pharmacotherapy in preclinical studies of ASD.

Keywords: autism, animal behavior, purinergic system, suramin, valproate. 


\section{INTRODUCTION}

Autism Spectrum Disorder (ASD) is a neurodevelopmental disorder characterized by impairments in communication and social interaction and repetitive or stereotyped behaviors (American Psychiatric Association, 2013). In the last years, the prevalence of ASD had a strong elevation (1:59 live births according to the most recent data from USA) (Baio et al., 2018), explained only in part by the changes in diagnostic parameters of DSM-5, demonstrating the necessity to expand studies in order to understand the pathways and possible risk factors involved in this disorder. Although the etiology is still unclear, it is already known that genetic and environmental factors are determinant for shaping the heterogeneous phenotypes exhibited by individuals with ASD (Chaste and Leboyer, 2012). The inflammatory dysregulation might appear as a potential etiological factor in neurodevelopmental

disorders (Boulanger-Bertolus et al., 2018), such as ASD (Elias et al., 2015). Several studies demonstrated that the use of valproic acid (VPA) - an anticonvulsant drug widely used in the treatment of epilepsy, migraine and mood instabilities - during pregnancy, especially in the first trimester, can significantly increase the risk of developing autism (Christensen et al., 2013; Williams et al., 2001).

Prenatal exposure to VPA is one of the best characterized rodent models of autism with strong construct, face, and predictive validity (Mabunga et al., 2015; Roullet et al., 2013). Male offspring of dams injected with VPA on E12,5 show autistic-like brain abnormalities and a plethora of behavioral aberrations including decreased social behavior (Bambini-Junior et al., 2011), hyperactivity and stereotypies (Schneider and Przewłocki, 2005), increased anxiety, lower sensitivity to pain and diminished acoustic prepulse inhibition (Schneider and Przewłocki, 2005), resembling both core symptoms (Schneider and Przewłocki, 2005) and the 
most significant neurobehavioral derangements observed in autism (Fontes-Dutra et al., 2018; Lin et al., 2013; Markram et al., 2008). VPA offspring express also molecular and immunological aberrations including altered functioning of opioidergic (Schneider et al., 2007), serotonergic (Tsujino et al., 2007), dopaminergic (Nakasato et al., 2008), GABAergic (Robertson et al., 2016) and glutamatergic (Horder et al., 2018) systems, decreased cellular immunity (Gottfried et al., 2015), electrophysiological impairments (Gogolla et al., 2009) and cytoarchitecture disruptions (Casanova et al., 2002; Fontes-Dutra et al., 2018; Hutsler and Casanova, 2016). Thus, it became necessary to understand how VPA induces developmental alterations that lead to ASD analyzing, for example, modulation of different components of synaptic transmission, like the purinergic system.

Several studies have demonstrated mitochondrial dysfunctions in ASD (Filipek et al., 2003; Patowary et al., 2017). This impairment of mitochondrial energetic metabolism and consequent increase in extracellular ATP levels (Faas et al., 2017) leads to the onset of inflammatory processes via purinergic signaling, suggesting that this system may be involved in the etiology of ASD. Experimental evidence indicate the participation of ATP-activated P2X and P2Y purinergic receptors in embryonic brain development as well as in adult neurogenesis for maintenance of normal brain functions (Glaser et al., 2013; Oliveira and Ulrich, 2016; Ulrich et al., 2012) and alterations in this context have been already related to psychiatric disorders, like autism (Cheffer et al., 2018). Previous studies demonstrated that suramin, a non-selective inhibitor of the purinergic system, has therapeutic effects on autistic-like behaviors in the animal model of autism through maternal immune activation (MIA) (Naviaux et al., 2014, 2013). Studies have shown that purinergic system could prevent behavioral changes in this animal model, which 
seem to be related with elevated levels of interleukin 6 (IL-6)(Smith et al., 2007). Interestingly, the Naviaux's group recently demonstrated in a small, phase I/II, randomized clinical trial that a single intravenous dose of suramin was associated with improved scores for language, social interaction, and decreased restricted or repetitive behaviors. The five children who received placebo had no improvements these parameters (Naviaux et al., 2017). However, it is still unclear how the inflammatory response and the purinergic system is being modulated by both prenatal effect by VPA and post-natal treatment with the anti-purinergic suramin.

Based on these previous findings, the aim of this work was to evaluate the therapeutic effects of suramin on several behaviors in an animal model of autism induced by prenatal exposure to VPA and elucidate the role of purinergic signaling on inflammatory responses in autism context.

\section{METHODS}

\subsection{Animals and ethics}

Wistar rats obtained from the local breeding colony (ICBS-Federal University of Rio Grande do Sul) were maintained under standard laboratory conditions. The animals were mated overnight, and when pregnancy was established by the presence of spermatozoa in the vaginal smear, this day was considered the zero embryonic day (E0). The offspring was weaned at postnatal day 21 (P21) and only male animals were used in this study (Bambini-Junior et al., 2011). This project was approved by the local animal ethics committee (CEUA-UFRGS 23884) and all procedures were approved by the Institutional Ethics Committee on Animal Use in accordance with Brazilian Law 11794/2008 (Arouca Law) and National Institutes of Health guide for the care and use of Laboratory animals (NIH Publications No. 8023). 


\subsection{Treatments}

Valproic acid (sodium valproate, Sigma-Aldrich, USA) was dissolved in $0.9 \%$ saline to a final concentration of $250 \mathrm{mg} / \mathrm{mL}$. Pregnant females received a single intraperitoneal injection of $600 \mathrm{mg} / \mathrm{kg}$ VPA or physiological saline on E12.5. Male offspring received a single intraperitoneal injection of suramin (hexasodium salt, Sigma-Aldrich, USA) at $20 \mathrm{mg} / \mathrm{kg}$ or its vehicle $0.1 \mathrm{M}$ PBS on P30. Thus, four experimental groups were formed: Control (only vehicles injected), suramin (SUR), VPA and VPA + SUR. The litters were split equally among the experimental groups proposed by the present work as it follows: if the litter size presented an even number, half received suramin treatment and the other half, PBS treatment. If the litter size presented an odd number, for example, the size of three, two rats received suramin treatment and one rat received PBS treatment, and vice versa, randomly.

\subsection{Behavioral tests}

Behavioral testing was performed in offspring, between P32-P40, starting two days after the injection of suramin. All behavioral tests were performed under light conditions of 60 LUX by experienced researchers using a double-blind approach. The following behavioral tests were performed: elevated plus maze, open field/grooming, whisker nuisance task (WNT), three-chambered test, reciprocal sociability test and tail flick test. Except for the WNT and tail flick, all tests were videotaped for later evaluations.

2.3.1. Elevated Plus Maze (P32): The anxiety-like behavior was assessed in an elevated plus maze apparatus with a $10 \mathrm{~cm} \times 10 \mathrm{~cm}$ center, connecting two opposite open arms (length: $50 \mathrm{~cm}$ ) and two opposite arms closed with $30 \mathrm{~cm}$ high walls (length: $50 \mathrm{~cm}$ ), $1 \mathrm{~m}$ above the floor. Rats were placed in the middle of apparatus and its movements were 
recorded for 5 minutes using a camera connected to a laptop. The time spent in the closed arms is considered a measure of anxious behavior.

2.3.2. Open Field Test/Self-Grooming (P33): Adapted from Schneider and colleagues (Schneider and Przewłocki, 2005), the exploratory and locomotor activity and the time and number of stereotyped movements (self-grooming behavior) were assessed in an open field arena, which consists of a wooden box measuring $50 \times 50 \times 50 \mathrm{~cm}$. Rats were placed in the center of the arena and recorded during 30 minutes. Using the Anymaze Software $\AA$, we performed a tracking of locomotor activity (travelled distance and average speed) and time spent and number of entries in the central during the 30 minutes of test.

The self-grooming behavior was evaluated considering three different time periods (0-5, 10-15 and 20-25 minutes). We considered grooming as number of body cleaning with paws and face-washing actions and distinguished between complete (cleaning from snout to tail) and incomplete (fast and repetitive movements on snout) self-grooming.

2.3.3. Whisker Nuisance Task (P34-35): Adapted from McNamara et al (McNamara et al., 2010) and described by Fontes-Dutra and colleagues (Fontes-Dutra et al., 2018), in this test we observed the animal response to the vibrissae stimulation. One day prior to test, animals were set to the experimenter for 5 minutes, in an empty housing $(57.1 \times 39.4 \times 15.2 \mathrm{~cm})$ coated with an absorbent pad. On the day of test, the vibrissae were stimulated with a wooden toothpick for three consecutive periods of 5 $\min (15 \mathrm{~min}$ in total) with a 30 seconds interval between them. McNamara et al. (2010) developed a nonparametric scale of 0 to 2 
according to the response $(0=$ absent/typical, $1=$ present/light response and $2=$ profound/accentuated response), distributed in 8 categories of behavior: freezing, stance and body position, breathing, whisker position, whisking response, evading stimulation, response to stick presentation and grooming (McNamara et al., 2010). The maximum test score is 16 . High scores (8-16) indicate abnormal responses to stimulation, in which the animal freezes, shakes, or is aggressive. The low scores (0-4) indicate normal responses, in which the rat is calm or indifferent to stimulation.

2.3.4. Three-Chamber Test (P36-37): This test was performed as previously described by Bambini-Junior and colleagues (Bambini-Junior et al., 2011). Briefly, at the beginning, the animal was habituated in the central chamber of the apparatus for 5 minutes. In the Sociability Test, one object was placed in one of the side chambers and in the other an unknown interaction animal (novel rat 1). We measured the time spent in each chamber and the time of exploration of either the rat or the object for 10 minutes.

In the Social Novelty Test, the novel rat 1 (now known rat) remained in this place and an unknown rat (novel rat 2 - an unfamiliar and younger 21-28 days old Wistar rat) was placed in the previously empty chamber. The time spent in each chamber and the time of exploration of both the rat known or not was also evaluated for 10 minutes.

2.3.5. Reciprocal Social Behavior (P38): Adapted from Schneider et al. (Schneider and Przewłocki, 2005), the test was performed in the same box as the open field test during 15 minutes. The test animal was placed 
in the apparatus and, after a habituation period of 5 minutes, an unfamiliar and younger Wistar rat (21-28 days old) interaction animal was placed with the test animal. We evaluated the social behavior of the test animal using time and number of nose to nose interaction, anogenital inspection, flank exploration and following.

2.3.6. Tail Flick (P39-40): Nociceptive thresholds were evaluated using a tail flick analgesimeter (Insight Equipments, Ribeirão Preto, Brazil). One day prior the test, the animals were gently restrained by hand for 5 minutes in order to habituate to apparatus. Tail flick measurements were taken three times at 30 -seconds intervals.

\subsection{Tissue samples}

The animals were deeply anesthetized on P41 with ketamine $(300 \mathrm{mg} / \mathrm{Kg})$ and xilazine $(40 \mathrm{mg} / \mathrm{Kg})$. After, the animals were decapitated, and the medial prefrontal cortex and hippocampus were dissected. The tissues were immediately homogenized in TRIzol ${ }^{\circledR}$ reagent (Invitrogen, USA) and preserved at ultra-freezer until posterior molecular analysis.

2.4.1. RNA Extraction and RT-qPCR Procedure: After homogenization of tissues samples, chloroform was added to perform phase separation, and RNA was precipitated from the upper aqueous layer using isopropanol. The precipitated RNA was washed with ethanol to remove impurities, resuspended in RNase-free water and stored at ultra-freezer (Hummon et al., 2007).

The mRNA transcription levels of purinergic receptors and cytokines were evaluated by reverse transcriptase followed by quantitative polymerase chain reaction (RT-qPCR). Complementary DNA (cDNA) 
was synthesized from mRNA using reverse transcriptase reaction containing $2 \mu \mathrm{g}$ of total RNA, $1 \mu \mathrm{L}$ of $10 \mathrm{mM}$ dNTP mix (Invitrogen, USA), $1 \mu \mathrm{L}$ of oligodT primer, $4 \mu \mathrm{L}$ M-MLV reverse transcriptase $5 \mathrm{X}$ reaction buffer (Invitrogen, USA), $2 \mu \mathrm{L}$ of $0.1 \mathrm{M}$ DTT (Invitrogen, USA), 1 $\mu \mathrm{L}$ of RNase inhibitor (Invitrogen, USA), 1.0 $\mu \mathrm{L}$ of M-MLV reverse transcriptase (Invitrogen, USA), and sterile distilled water to a final volume of $20 \mu \mathrm{L}$. The synthesis of the cDNA was completed after a sequence of three incubations at $65^{\circ} \mathrm{C}$ for $5 \mathrm{~min}, 37^{\circ} \mathrm{C}$ for $50 \mathrm{~min}$ and $70^{\circ} \mathrm{C}$ for $15 \mathrm{~min}$.

The quantitative PCR mix was comprised by $8 \mu \mathrm{L}$ of $\mathrm{CDNA}(1: 40)$ and 12 $\mu \mathrm{L}$ reaction mix containing $0.5 \mu \mathrm{L}$ of $10 \mu \mathrm{M}$ dNTP mix (Invitrogen, USA), $2.0 \mu \mathrm{L}$ of 10X PCR buffer (Invitrogen, USA), $0.8 \mu \mathrm{L}$ of $50 \mathrm{mM} \mathrm{MgCl} 2$ (Invitrogen, USA), $2.0 \mu \mathrm{L}$ of $1 \mathrm{X} \mathrm{SYBR}^{\mathrm{TM}}$ Green (Molecular Probes, USA), $0.1 \mu \mathrm{L}$ of Platinum Taq DNA Polymerase (Invitrogen, USA), 0.2 $\mu \mathrm{L}$ of specific forward and reverse $(10 \mu \mathrm{M})$ primers (as specified in Supplementary Table 1) and sterile distilled water to a final volume of 20 $\mu \mathrm{L}$. The fluorescence of SYBR ${ }^{\mathrm{TM}}$ Green was used to detect amplification, estimate Ct values, and to determine specificity after melting curve analysis. PCR cycling conditions were standardized to $95^{\circ} \mathrm{C}$ for $5 \mathrm{~min}$ followed by 40 cycles at $95^{\circ} \mathrm{C}$ for $10 \mathrm{~s}, 58^{\circ} \mathrm{C}$ for $10 \mathrm{~s}$, and $72^{\circ} \mathrm{C}$ for $10 \mathrm{~s}$. After the main amplification, sample fluorescence was measured from $60^{\circ} \mathrm{C}$ to $95^{\circ} \mathrm{C}$, with an increasing ramp of $0.3^{\circ} \mathrm{C}$ each, to obtain the denaturing curve of the amplified products and Tm estimation, to assure their homogeneity after peak detection. Data was obtained from an Applied Biosystems StepOne System (USA). 
The RT-qPCR results were imported into Microsoft Excel and the geNorm program was used to assess the variance in expression levels of the mRNA analyzed (Vandesompele et al., 2002). This program scanned all mRNA evaluated and ranked accordingly to their stability. The more stable mRNAs were used as endogenous expression controls. PCR efficiency was calculated from the slope of the amplification curve by exponential amplification analysis using the LinRegPCR algorithm (Ramakers et al., 2003). The relative expression of mRNA was calculated considering the $100 \%$ PCR efficiency and the $-\Delta \Delta C$ t values for each mRNA (Livak and Schmittgen, 2001) and were normalized to the housekeeping genes identified by the geNorm software.

\subsection{Statistical analysis}

IBM SPSS Statistics 20.0 (IBM SPSS, Armonk, NY, USA) was used to perform the statistical analysis. Kolgomorov-Smirnov and Shapiro-Wilk tests of normality were applied to determine data distribution. For behavioral tests, we used Generalized Estimating Equations (GEE) to weight both the interventions (VPA exposure and/or suramin treatment) and the litter effect in the behavioral outcome. Considering that GEE is a flexible method based on general linear models, allowing the analysis of data with different distribution patterns, this protocol was utilized to compare different correlated variables(Fontes-Dutra et al., 2019). We also divided the litter equally among the experimental groups.After a Wald Chi-Square test, we performed pairwise comparisons for the parameters that presented interaction effect between interventions (VPA-by-suramin interaction). If only main effects were observed, the individual effect of VPA or suramin was evaluated. Bonferroni's post hoc test was used as the final evaluation. Data is reported as mean \pm standard error 
of the mean (SEM). The Poisson distribution was used for discrete variables (number), while gamma distribution was used for time variables.

The relative expressions of purinergic receptors and cytokines were compared using one-way ANOVA followed by Bonferroni. The results were expressed as mean \pm SEM. All statistical analyzes were supervised by the Biostatistics Unit at the Clinical Hospital of Porto Alegre.

\section{RESULTS}

\subsection{Behavioral tests}

3.1.1. Social behavior analysis in the three-chambered test: Rats from control and suramin group spent significantly more time in the chamber containing a conspecific novel rat than a novel object (CON: $p<0.001$; SUR: $p=0.025$; Figure $1 A$ ). In contrast, VPA animals did not present preference between spending time in the chamber with a rat or an object $(p=0.550)$. Interestingly, suramin treatment of VPA-exposed rats was able to reestablish the social feature, as the VPA+SUR group showed preference to stay in the chamber together with the novel rat $(p<0.001)$. Concerning social interaction, rats from both control and suramin groups also spent significantly more time exploring the cage containing the conspecific rather than the object (CON: $p<0.001$ SUR: $p<0.001)$, while the VPA group showed no preference between rat and object exploration $(p=0.131$, Figure $1 A)$. Suramin treatment was again able to restore this social behavior (VPA+SUR: $p<0.001)$.

In the test for social novelty, all groups showed no significant difference between the time spent in the novel rat chamber and the known rat chamber (CON: $p=0.562$; SUR: $p=0.760$; VPA: $p=1.000$; VPA+SUR: 
$p=0.235$; Figure 1B). However, rats from control and suramin groups spent significantly more time exploring the novel rat than the known rat (CON: $p=0.003$; SUR: $p=0.005$, Figure $1 B$ ), indicating an interest in social novelty. VPA rats did not show preference in exploration time between novel and known rat (VPA: $p=0.13$ ), whilst suramin treatment was able to prevent this social impairment in VPA-exposed animals (VPA+SUR: $p=0.016$, Figure 1B).

3.1.2. Reciprocal social behavior: Prenatal exposure to VPA significantly reduced every reciprocal social interaction parameter evaluated, except for following behavior (Supplementary Figure S1). We observed only a VPA effect on total reciprocal social behavior, since VPA-exposed animals presented a decrease in number $(p<0.001)$ and time $(p<0.001)$ of social approaches and suramin treatment was not able to rescue these impairments (Figure 1C).

3.1.3. Anxiety-like, exploratory and locomotor behavior: Rats from VPA group spent significantly less time exploring the open arm of the elevated plusmaze apparatus, compared to animals from control $(p=0.001)$ and suramin $(p=0.003)$ groups. VPA+SUR group spent more time exploring the open arm of the apparatus compared to the VPA group $(p<0.001$; Figure $2 \mathrm{~A}$ ), indicating that suramin was able to rescue the anxiety-like behaviors in rats exposed to VPA. It is worth to note that no differences were found among experimental groups in open arms entries (all $p>0.570$; Supplementary Figure S2A) and number of risk assessments in the elevated plus-maze apparatus (all $p>0.210$; Supplementary Figure S2B). In the open field arena, animals from VPA group spent 
significantly less time in central square compared to animals from control $(p=0.007)$ and suramin $(p<0.001)$ groups. As observed in plus maze evaluation, suramin was able to rescue this alteration, since VPA+SUR group spent more time in central square compared to VPA group $(p=0.004$, Figure 2B).

Concerning the exploratory behavior, only the VPA-exposed rats presented lower number of rearing in an open field arena $(p=0.041$, Figure 2C). Finally, when locomotor activity of those rats in the open field arena was evaluated, no significant differences in distance traveled (all $p>0.910$, Figure 2D) and average speed (all $p>0.960$, Supplementary Figure S2D) were found among experimental groups.

3.1.4. Self-grooming behavior: The self-grooming behavior was evaluated across three testing periods (0-5, 10-15 and 20-25 minutes) and distinguished between complete and incomplete self-grooming. During the second period, VPA groups spent more time performing complete self-grooming compared to control animals $(p=0.039)$, and suramin was not able to rescue from this altered behavior. Similarly, in the third period, the same pattern was observed in VPA animals $(p=0.003$, Table 1). Taking all periods together, VPA-exposed animals spent more time doing complete self-grooming with no reversion by suramin treatment in this behavior $(p=0.002$, Figure $3 A)$.

Regarding to the time spent doing incomplete self-grooming, no difference was observed among the groups (all p>0.100, Table 1 or $p>0.420$, Figure $3 C$ ). However, the VPA group presented a trend to spend more time self-grooming in $10-15 \mathrm{~min}(p=0.065)$, a significant 
increase in the third period $(p=0.013$, Table 1$)$, considering the three periods of test ( $p=0.002$, Figure $3 \mathrm{E})$. In all cases, postnatal treatment with suramin was not able to rescue from these alterations.

Concerning the number of self-grooming events, VPA animals presented more events of complete self-grooming only in the third period $(p=0.002$, Table 1) with a trend to increased total complete self-grooming $(p=0.088$, Figure 3B). When considered the number of incomplete self-grooming and all grooming events, no differences were observed among groups in the three periods analyzed (all p $>0.210$, Table 1 ) or considering three periods together (all $p>0.553$, Figure 3D). Finally, when considered the number of all events of self-grooming, VPA-exposed animals presented an increase only following $20-25$ minutes $(p=0.005$, Table 1$)$ with no differences in the total period of test (all $p>0.130$, Figure $3 F$ ).

3.1.5. Sensory Behavior: In the whisker nuisance task (WNT), VPA-exposed animals presented a significant increased score when compared to control animals ( $p=0.001$, Figure $4 A$ ), indicating higher levels of nuisance when whiskers are stimulated. The postnatal treatment with suramin was not able to rescue this alteration.

Only a VPA effect was observed in the latency to tail withdrawal in nociceptive tail flick test, so that VPA-exposed animals presented higher latencies compared to non-exposed animals ( $p=0.012$, Figure 4B).

\subsection{Molecular analysis}

3.2.1. Expression of purinergic receptors: The relative expression of $m R N A$ was performed in the medial prefrontal cortex. GeNorm algorithm ranked P2Y2 and P2Y4 as most stable and they were used as housekeeping to 
evaluate the relative expression of the remaining receptors. The expression rate of the ionotropic receptor P2X4 was significantly increased in the cortex of animals prenatally exposed to VPA and suramin was not able to revert this alteration $(F(3,28)=11,98 ; p<0.0001)$ (Figure 5A). On the other hand, there were no significant differences in levels of remaining receptors (Figure $5 \mathrm{~A}$ ).

When the receptors were evaluated in hippocampus of the young rats, P2X3 and P2Y4 were used as housekeeping. Curiously, the ionotropic receptor P2X4 was found significantly increased in animals from VPA and VPA+SUR groups, compared to control group also in this region $(F$ $(3,28)=6,020 ; p=0.0027)$. Additionally, animals presented increased mRNA levels coding for metabotropic receptor P2Y2 in VPA and VPA+SUR group compared to control group $(F(3,28)=6,194$; $p=0.0023$ ). In both cases, suramin was not able to reverse this alteration (Figure 5B). Nevertheless, levels of remaining purinergic receptors showed no differences among experimental groups (Figure 5B).

3.2.2. Expression of cytokine mRNA levels: In the medial prefrontal cortex, considering GAPDH and Beta3-tubulin as housekeeping genes, the animals from VPA group presented an increase in relative expression of IL-6 mRNA compared to control group $(F(3,24)=5,406 ; p=0.005)$ and the postnatal treatment with suramin rescued the levels of IL-6 of VPAexposed rats to control levels (Figure $6 \mathrm{~A}$ ). On the other hand, IL-1 $\beta$, IFN$Y$ and TNF- $\alpha$ showed no differences between groups. Regarding to hippocampus and considering the same housekeeping mRNA, no 
differences were found in cytokine levels among all experimental groups (Figure 6B).

\section{DISCUSSION}

An important approach in VPA model is the possibility of developing therapeutic strategies to attenuate several features observed in ASD. For instance, our group demonstrated that resveratrol (RSV), an antioxidant and anti-inflammatory molecule, prevents VPA-induced social impairments in the three-chamber test (Bambini-Junior et al., 2014) and in the number and time of reciprocal social interactions (Hirsch et al., 2018). The present results corroborate impairments in sociability and social novelty exploration in the three-chamber test, as previously demonstrated (Bambini-Junior et al., 2014, 2011). As previously shown, the postnatal treatment with a single dose of suramin was able to rescue social impairments (Naviaux et al., 2014). It is important to consider that there could be different schedules of administration of suramin, but considering its half-life and relevant clinical data, here we employed a single doses of antipurinergic treatment.

Additionally, the decrease in total reciprocal social interaction was not reversed by suramin. In fact, the reciprocal social behavior test involves complex patterns of socialization between two free animals, unlike the three-chamber test, where the conspecific animal remains trapped in a cage. Therefore, this characteristic of the test could be forcing the analyzed animal towards more complex social behavior actions, possibly causing additional impairments not reversed by suramin.

Another main finding of our study was that VPA rats presented a more anxious-like behavior compared to control animals as seen in plus maze apparatus 
and open field arena. Anxiety behavior is one of most common comorbidities in ASD and has been reported to be present in around $50 \%$ of autistic children and adolescents (Simonoff et al., 2008; van Steensel et al., 2011). Our study corroborates previous studies that demonstrated increased anxiety-like behavior in animal models of autism (Patterson, 2011). Interestingly, the treatment with suramin was able to rescue completely this alteration, which was seen by the higher percentage of total time spent exploring the open arm of the apparatus compared to VPA group.

We also observed that VPA-exposed animals do not present significant motor alterations or hyperactivity, but demonstrated a significant reduction in vertical exploratory activity, which could be related to the reduction in social interest of VPA animals described in sociability test, since animals with less exploratory tendencies possibly have impairments related to social approach. As observed in reciprocal sociability test, the postnatal treatment with suramin was not able to rescue the impairments observed in this exploratory behavior.

In addition to analyzing social behavior, the present study also assessed another core symptom of autism - the repetitive and stereotyped behavior. In animal models of autism, this feature can be measured by analyzing the repetitive selfgrooming behavior. In present work, we assessed separately the self-grooming behavior as complete and incomplete events. The VPA-exposed animals showed increased time of complete self-grooming, without alteration in both number and time of incomplete grooming. Studies have demonstrated that only complete grooming is initiated by cerebellar midline or locus coeruleus stimulation (Strazielle et al., 2012) and that ATP can induce depolarization and increase excitability of norepinephrinergic system from locus coeruleus, possibly mediated by specific 
modulators of P2 receptors (Masaki et al., 2001; Yao and Lawrence, 2005), suggesting a putative role of purinergic system in grooming outcomes.

Previous studies already demonstrated that grooming behavior could be related to sensory components (Houghton et al., 2018). Corroborating a previous work from our group (Fontes-Dutra et al., 2018), we observed that VPA animals presented hypersensitivity to a non-harmful stimulus in WNT, suggesting a disturbance in sensory gating which could lead to increase in self-grooming behavior. Hyposensitivity to pain is also frequently observed in autistic subjects, although this feature is not a consensus, since different findings were observed depending on how the studies were conducted (Moore, 2015). In our study, VPAexposed rats presented higher latencies to sense a thermal stimulus, indicating a lower nociceptive reactivity in accordance to previous work (Schneider et al., 2008). Postnatal treatment with suramin was not able to rescue these sensorial impairments in VPA animals. Taking together, in the present work we demonstrated that VPAinduced alterations in behavioral components related to social and anxiety behavior in the animal model of ASD can be modulated by the anti-purinergic molecule suramin, highlighting the role of purinergic system in the pathophysiology of ASD.

There are only a few studies in literature indicating the roles of purinergic system in sensory processing. Nevertheless, it is known that purinergic system plays important roles in sensory pathways (Irnich et al., 2002). Our data presented increased expression of cortical heteromeric P2X4 receptor in VPA-exposed animals. Since this receptor is involved with immunological responses in several tissues, the involvement of purinergic signaling in the ASD pathophysiology may be related to neuroimmunological alterations, as already found in patients (Gottfried et al., 2015) and animal models of autism (Wei et al., 2012; Xu et al., 2015). It is 
already known that suramin has therapeutic effects on social deficits (Naviaux et al., 2014, 2013), although it is poorly able to cross the blood brain barrier (Hawking, 1978; Roboz et al., 1998). Our hypothesis is that suramin could be acting only at peripheral levels and modulates some characteristics of autism, possibly through a crosstalk between immunological and central nervous systems of these animals.

Our study demonstrated that animals from VPA group showed increased levels of pro-inflammatory cytokine IL-6 in medial prefrontal cortex. Interestingly, a remarkable finding in the present work was the restoration IL-6 levels in this area after treatment with suramin. Since the levels of this cytokine are commonly increased in autistic patients (Gottfried et al., 2015) and in animal models of autism (Wei et al., 2012; Xu et al., 2015), the suramin-induced effect on IL-6 levels could play a role on its changes in social and anxiety-like behavior (Xu et al., 2015), which

also has been rescued by suramin treatment. Therefore, the present data contribute to the understanding of how purinergic system is being modulated in VPA animal model of ASD, elucidating important VPA-induced alterations in ASD-related behaviors, changing both the expression pattern of purinergic receptors in medial prefrontal cortex and hippocampus, and the levels of IL-6, potentially pointing to roles in purinergic system and inflammation status in VPA animal model. By contrast, postnatal treatment by suramin was capable to prevent alterations in social and anxiety-like behavior induced by VPA prenatal exposure, concomitantly reverting the levels of IL-6 in the same model.

\section{CONCLUSION}

In summary, our findings reinforce the idea of antipurinergic therapy as a novel pharmacological target in disorders associated with inflammatory 
dysregulation, including autism and provide new insights for the development of effective and safe treatments. Although VPA-exposed animals seem to present higher permeability in blood-brain barrier (Kumar et al., 2015; Kumar and Sharma, 2016a, 2016b), the limited access of suramin to CNS could explain the limitations of suramin-based therapeutic strategies. Even though suramin has been used in humans for more than 100 years as a therapeutic agent, it has plethora of important dose-dependent side effects. However, the present data provide remarkable support for the hypothesis that a drug acting through peripheral immune and inflammatory components can modulate some molecular and behavioral alterations in VPA autism model. As pointed out in a recent review (Burnstock, 2018), the development of purinergic compounds for the treatment of a wide variety of diseases is still in its infancy, but for sure, suramin studies open an important window for new drug designs and therapies. Further studies are necessary to elucidate the mechanisms of suramin action. In addition to this, the use of some specific and safer drugs could be more efficient to rescue autistic-related impairments.

\section{CONFLICT OF INTEREST}

The authors declare that there are no conflicts of interest.

\section{FUNDING}

This work was supported by the Brazilian National Institute of Science and Technology on Neuroimmunomodulation (INCT-NIM), Rio de Janeiro, Brazil; National Council of Technological and Scientific Development (CNPq); Coordination for the Improvement of Higher Education Personnel (CAPES), São Paulo Research 
Foundation (FAPESP Project No. 2012/50880-4) and Clinical Hospital of Porto Alegre (FIPE-HCPA).

\section{REFERENCES}

American Psychiatric Association, 2013. Diagnostic and Statistical Manual of Mental Disorders, 5th Edition (DSM-5), Diagnostic and Statistical Manual of Mental Disorders 4th edition TR.

https://doi.org/10.1176/appi.books.9780890425596.744053

Baio, J., Wiggins, L., Christensen, D.L., Maenner, M.J., Daniels, J., Warren, Z., Kurzius-Spencer, M., Zahorodny, W., Robinson Rosenberg, C., White, T., Durkin, M.S., Imm, P., Nikolaou, L., Yeargin-Allsopp, M., Lee, L.-C., Harrington, R., Lopez, M., Fitzgerald, R.T., Hewitt, A., Pettygrove, S., Constantino, J.N., Vehorn, A., Shenouda, J., Hall-Lande, J., Van Naarden Braun, K., Dowling, N.F., 2018. Prevalence of Autism Spectrum Disorder Among Children Aged 8 Years - Autism and Developmental Disabilities Monitoring Network, 11 Sites, United States, 2014. MMWR. Surveill. Summ. 67, 1-23.

https://doi.org/10.15585/mmwr.ss6706a1

Bambini-Junior, V., Rodrigues, L., Behr, G.A., Moreira, J.C.F., Riesgo, R., Gottfried, C., 2011. Animal model of autism induced by prenatal exposure to valproate: Behavioral changes and liver parameters. Brain Res. https://doi.org/10.1016/j.brainres.2011.06.015

Bambini-Junior, V., Zanatta, G., Della Flora Nunes, G., Mueller de Melo, G., Michels, M., Fontes-Dutra, M., Nogueira Freire, V., Riesgo, R., Gottfried, C., 2014. Resveratrol prevents social deficts in animal model of autism induced by valproic acid. Neurosci. Lett. https://doi.org/10.1016/j.neulet.2014.09.039 
Boulanger-Bertolus, J., Pancaro, C., Mashour, G.A., 2018. Increasing Role of Maternal Immune Activation in Neurodevelopmental Disorders. Front. Behav. Neurosci. 12, 230. https://doi.org/10.3389/fnbeh.2018.00230

Burnstock, G., 2018. The therapeutic potential of purinergic signalling. Biochem. Pharmacol. 151, 157-165. https://doi.org/10.1016/j.bcp.2017.07.016

Casanova, M.F., Buxhoeveden, D.P., Switala, A.E., Roy, E., 2002. Minicolumnar pathology in autism. Neurology 58, 428-32.

Chaste, P., Leboyer, M., 2012. Autism risk factors: genes, environment, and geneenvironment interactions. Dialogues Clin. Neurosci. 14, 281-92.

Cheffer, A., Castillo, A.R.G., Corrêa-Velloso, J., Gonçalves, M.C.B., Naaldijk, Y., Nascimento, I.C., Burnstock, G., Ulrich, H., 2018. Purinergic system in psychiatric diseases. Mol. Psychiatry 23, 94-106. https://doi.org/10.1038/mp.2017.188

Christensen, J., Grønborg, T.K., Sørensen, M.J., Schendel, D., Parner, E.T., Pedersen, L.H., Vestergaard, M., 2013. Prenatal Valproate Exposure and Risk of Autism Spectrum Disorders and Childhood Autism. JAMA 309, 1696-1703. https://doi.org/10.1001/jama.2013.2270

Elias, R., Sullivan, J.B., Lee, Y.W., White, S.W., 2015. Exploring the Potential Role of Inflammation as an Etiological Process in ASD. Rev. J. Autism Dev. Disord. 2, 273-286. https://doi.org/10.1007/s40489-015-0051-z

Faas, M.M., Sáez, T., de Vos, P., 2017. Extracellular ATP and adenosine: The Yin and Yang in immune responses? Mol. Aspects Med. https://doi.org/10.1016/j.mam.2017.01.002

Filipek, P.A., Juranek, J., Smith, M., Mays, L.Z., Ramos, E.R., Bocian, M., MasserFrye, D., Laulhere, T.M., Modahl, C., Spence, M.A., Gargus, J.J., 2003. 
Mitochondrial dysfunction in autistic patients with $15 q$ inverted duplication. Ann. Neurol. 53, 801-4. https://doi.org/10.1002/ana.10596

Fontes-Dutra, M., Della-Flora Nunes, G., Santos-Terra, J., Souza-Nunes, W., BauerNegrini, G., Hirsch, M.M., Green, L., Riesgo, R., Gottfried, C., Bambini-Junior, V., 2019. Abnormal empathy-like pro-social behaviour in the valproic acid model of autism spectrum disorder. Behav. Brain Res. 364, 11-18.

https://doi.org/10.1016/J.BBR.2019.01.034

Fontes-Dutra, M., Santos-Terra, J., Deckmann, I., Brum Schwingel, G., Della-Flora Nunes, G., Hirsch, M.M., Bauer-Negrini, G., Riesgo, R.S., Bambini-Júnior, V., Hedin-Pereira, C., Gottfried, C., 2018. Resveratrol Prevents Cellular and Behavioral Sensory Alterations in the Animal Model of Autism Induced by Valproic Acid. Front. Synaptic Neurosci. 10, 9.

https://doi.org/10.3389/fnsyn.2018.00009

Glaser, T., Resende, R.R., Ulrich, H., 2013. Implications of purinergic receptormediated intracellular calcium transients in neural differentiation. Cell Commun. Signal. 11, 12. https://doi.org/10.1186/1478-811X-11-12

Gogolla, N., LeBlanc, J.J., Quast, K.B., Südhof, T.C., Fagiolini, M., Hensch, T.K., 2009. Common circuit defect of excitatory-inhibitory balance in mouse models of autism. J. Neurodev. Disord. 1, 172-181. https://doi.org/10.1007/s11689-009$9023-x$

Gottfried, C., Bambini-Junior, V., Francis, F., Riesgo, R., Savino, W., 2015. The Impact of Neuroimmune Alterations in Autism Spectrum Disorder. Front. psychiatry 6, 121. https://doi.org/10.3389/fpsyt.2015.00121 Hawking, F., 1978. Suramin: with special reference to onchocerciasis. Adv.

Pharmacol. Chemother. 15, 289-322. 
Hirsch, M.M., Deckmann, I., Fontes-Dutra, M., Bauer-Negrini, G., Della-Flora Nunes, G., Nunes, W., Rabelo, B., Riesgo, R., Margis, R., Bambini-Junior, V., Gottfried, C., 2018. Behavioral alterations in autism model induced by valproic acid and translational analysis of circulating microRNA. Food Chem. Toxicol. 115, 336343. https://doi.org/10.1016/j.fct.2018.02.061

Horder, J., Petrinovic, M.M., Mendez, M.A., Bruns, A., Takumi, T., Spooren, W., Barker, G.J., Künnecke, B., Murphy, D.G., 2018. Glutamate and GABA in autism spectrum disorder-a translational magnetic resonance spectroscopy study in man and rodent models. Transl. Psychiatry 8, 106. https://doi.org/10.1038/s41398-018-0155-1

Houghton, D.C., Alexander, J.R., Bauer, C.C., Woods, D.W., 2018. Abnormal perceptual sensitivity in body-focused repetitive behaviors. Compr. Psychiatry 82, 45-52. https://doi.org/10.1016/j.comppsych.2017.12.005

Hummon, A.B., Lim, S.R., Difilippantonio, M.J., Ried, T., 2007. Isolation and solubilization of proteins after TRIzol extraction of RNA and DNA from patient material following prolonged storage. Biotechniques 42, 467-472.

Hutsler, J.J., Casanova, M.F., 2016. Review: Cortical construction in autism spectrum disorder: columns, connectivity and the subplate. Neuropathol. Appl. Neurobiol. 42, 115-134. https://doi.org/10.1111/nan.12227

Irnich, D., Tracey, D.J., Polten, J., Burgstahler, R., Grafe, P., 2002. ATP stimulates peripheral axons in human, rat and mouse--differential involvement of $A(2 B)$ adenosine and P2X purinergic receptors. Neuroscience 110, 123-9.

Kumar, H., Sharma, B., 2016a. Memantine ameliorates autistic behavior, biochemistry \& blood brain barrier impairments in rats. Brain Res. Bull. 124, 2739. https://doi.org/10.1016/j.brainresbull.2016.03.013 
Kumar, H., Sharma, B., 2016b. Minocycline ameliorates prenatal valproic acid induced autistic behaviour, biochemistry and blood brain barrier impairments in rats. Brain Res. https://doi.org/10.1016/j.brainres.2015.10.052

Kumar, H., Sharma, B.M., Sharma, B., 2015. Benefits of agomelatine in behavioral, neurochemical and blood brain barrier alterations in prenatal valproic acid induced autism spectrum disorder. Neurochem. Int. https://doi.org/10.1016/j.neuint.2015.10.007

Lin, H.-C.C., Gean, P.-W.W., Wang, C.-C.C., Chan, Y.-H.H., Chen, P.S., 2013. The Amygdala Excitatory/Inhibitory Balance in a Valproate-Induced Rat Autism Model. PLoS One 8, e55248. https://doi.org/10.1371/journal.pone.0055248 Livak, K.J., Schmittgen, T.D., 2001. Analysis of Relative Gene Expression Data Using Real-Time Quantitative PCR and the 2- $\Delta \Delta C T$ Method. Methods $25,402-$ 408. https://doi.org/10.1006/meth.2001.1262

Mabunga, D.F.N., Gonzales, E.L.T., Kim, J.-W., Kim, K.C., Shin, C.Y., 2015.

Exploring the Validity of Valproic Acid Animal Model of Autism. Exp. Neurobiol. 24, 285-300. https://doi.org/10.5607/en.2015.24.4.285

Markram, K., Rinaldi, T., Mendola, D. La, Sandi, C., Markram, H., 2008. Abnormal Fear Conditioning and Amygdala Processing in an Animal Model of Autism. Neuropsychopharmacology 33, 901-912. https://doi.org/10.1038/sj.npp.1301453

Masaki, E., Kawamura, M., Kato, F., 2001. Reduction by sevoflurane of adenosine 5'-triphosphate-activated inward current of locus coeruleus neurons in pontine slices of rats. Brain Res. 921, 226-32.

McNamara, K.C.S., Lisembee, A.M., Lifshitz, J., 2010. The whisker nuisance task identifies a late-onset, persistent sensory sensitivity in diffuse brain-injured rats. 
J. Neurotrauma 27, 695-706. https://doi.org/10.1089/neu.2009.1237

Moore, D.J., 2015. Acute pain experience in individuals with autism spectrum disorders: A review. Autism 19, 387-399. https://doi.org/10.1177/1362361314527839

Nakasato, A., Nakatani, Y., Seki, Y., Tsujino, N., Umino, M., Arita, H., 2008. Swim stress exaggerates the hyperactive mesocortical dopamine system in a rodent model of autism. Brain Res. 1193, 128-135.

https://doi.org/10.1016/j.brainres.2007.11.043

Naviaux, J., Schuchbauer, M., Li, K., Wang, L., Risbrough, V., Powell, S., Naviaux, R., 2014. Reversal of autism-like behaviors and metabolism in adult mice with single-dose antipurinergic therapy. Transl. Psychiatry 4.

https://doi.org/10.1038/tp.2014.33

Naviaux, R.K., Curtis, B., Li, K., Naviaux, J.C., Bright, A.T., Reiner, G.E., Westerfield, M., Goh, S., Alaynick, W.A., Wang, L., Capparelli, E. V., Adams, C., Sun, J., Jain, S., He, F., Arellano, D.A., Mash, L.E., Chukoskie, L., Lincoln, A., Townsend, J., 2017. Low-dose suramin in autism spectrum disorder: a small, phase I/II, randomized clinical trial. Ann. Clin. Transl. Neurol. 4, 491-505. https://doi.org/10.1002/acn3.424

Naviaux, R.K., Zolkipli, Z., Wang, L., Nakayama, T., Naviaux, J.C., Le, T.P., Schuchbauer, M.A., Rogac, M., Tang, Q., Dugan, L.L., Powell, S.B., 2013. Antipurinergic Therapy Corrects the Autism-Like Features in the Poly(IC) Mouse Model. PLoS One 8, e57380. https://doi.org/10.1371/journal.pone.0057380

Oliveira, Á., Ulrich, H., 2016. Purinergic receptors in embryonic and adult neurogenesis. Neuropharmacology 104, 272-281. https://doi.org/10.1016/J.NEUROPHARM.2015.10.008 
Patowary, A., Nesbitt, R., Archer, M., Bernier, R., Brkanac, Z., 2017. Next Generation Sequencing Mitochondrial DNA Analysis in Autism Spectrum Disorder. Autism Res. 10, 1338-1343. https://doi.org/10.1002/aur.1792 Patterson, P.H., 2011. Modeling Autistic Features in Animals. Pediatr. Res. 69, 34R40R. https://doi.org/10.1203/PDR.0b013e318212b80f

Ramakers, C., Ruijter, J.M., Deprez, R.H.L., Moorman, A.F.M., 2003. Assumptionfree analysis of quantitative real-time polymerase chain reaction (PCR) data. Neurosci. Lett. 339, 62-6.

Robertson, C.E., Ratai, E.-M., Kanwisher, N., 2016. Reduced GABAergic Action in the Autistic Brain. Curr. Biol. 26, 80-85. https://doi.org/10.1016/j.cub.2015.11.019

Roboz, J., Deng, L., Ma, L., Holland, J.F., 1998. Investigation of suramin-albumin binding by electrospray mass spectrometry. Rapid Commun. Mass Spectrom. 12, 1319-1322. https://doi.org/10.1002/(SICI)10970231(19981015)12:19<1319::AID-RCM332>3.0.CO;2-J

Roullet, F.I., Lai, J.K.Y., Foster, J.A., 2013. In utero exposure to valproic acid and autism - A current review of clinical and animal studies. Neurotoxicol. Teratol. 36, 47-56. https://doi.org/10.1016/j.ntt.2013.01.004

Schneider, T., Przewłocki, R., 2005. Behavioral Alterations in Rats Prenatally Exposed to Valproic Acid: Animal Model of Autism. Neuropsychopharmacology 30, 80-89. https://doi.org/10.1038/sj.npp.1300518

Schneider, T., Roman, A., Basta-Kaim, A., Kubera, M., Budziszewska, B., Schneider, K., Przewłocki, R., 2008. Gender-specific behavioral and immunological alterations in an animal model of autism induced by prenatal exposure to valproic acid. Psychoneuroendocrinology. 
https://doi.org/10.1016/j.psyneuen.2008.02.011

Schneider, T., Ziòłkowska, B., Gieryk, A., Tyminska, A., Przewłocki, R., 2007.

Prenatal exposure to valproic acid disturbs the enkephalinergic system functioning, basal hedonic tone, and emotional responses in an animal model of autism. Psychopharmacology (Berl). https://doi.org/10.1007/s00213-007-0795-y

Simonoff, E., Pickles, A., Charman, T., Chandler, S., Loucas, T., Baird, G., 2008.

Psychiatric disorders in children with autism spectrum disorders: prevalence, comorbidity, and associated factors in a population-derived sample. J. Am. Acad. Child Adolesc. Psychiatry 47, 921-9.

https://doi.org/10.1097/CHI.0b013e318179964f

Smith, S.E.P., Li, J., Garbett, K., Mirnics, K., Patterson, P.H., 2007. Maternal Immune Activation Alters Fetal Brain Development through Interleukin-6. J. Neurosci.

Strazielle, C., Lefevre, A., Jacquelin, C., Lalonde, R., 2012. Abnormal grooming activity in Dab1(scm) (scrambler) mutant mice. Behav. Brain Res. 233, 24-8. https://doi.org/10.1016/j.bbr.2012.04.038

Tsujino, N., Nakatani, Y., Seki, Y., Nakasato, A., Nakamura, M., Sugawara, M., Arita, H., 2007. Abnormality of circadian rhythm accompanied by an increase in frontal cortex serotonin in animal model of autism. Neurosci. Res. 57, 289-295. https://doi.org/10.1016/J.NEURES.2006.10.018

Ulrich, H., Abbracchio, M.P., Burnstock, G., 2012. Extrinsic Purinergic Regulation of Neural Stem/Progenitor Cells: Implications for CNS Development and Repair. Stem Cell Rev. Reports 8, 755-767. https://doi.org/10.1007/s12015-012-9372-9 van Steensel, F.J.A., Bögels, S.M., Perrin, S., 2011. Anxiety Disorders in Children and Adolescents with Autistic Spectrum Disorders: A Meta-Analysis. Clin. Child 
Fam. Psychol. Rev. 14, 302-317. https://doi.org/10.1007/s10567-011-0097-0

Vandesompele, J., De Preter, K., Pattyn, F., Poppe, B., Van Roy, N., De Paepe, A., Speleman, F., 2002. Accurate normalization of real-time quantitative RT-PCR data by geometric averaging of multiple internal control genes. Genome Biol. 3, RESEARCH0034.1-11.

Wei, H., Chadman, K.K., McCloskey, D.P., Sheikh, A.M., Malik, M., Brown, W.T., Li, X., 2012. Brain IL-6 elevation causes neuronal circuitry imbalances and mediates autism-like behaviors. Biochim. Biophys. Acta - Mol. Basis Dis. 1822, 831-842. https://doi.org/10.1016/J.BBADIS.2012.01.011

Williams, G., King, J., Cunningham, M., Stephan, M., Kerr, B., Hersh, J.H., 2001. Fetal valproate syndrome and autism: additional evidence of an association. Dev. Med. Child Neurol. 43, 202-6.

Xu, N., Li, X., Zhong, Y., 2015. Inflammatory cytokines: potential biomarkers of immunologic dysfunction in autism spectrum disorders. Mediators Inflamm. 2015, 531518. https://doi.org/10.1155/2015/531518

Yao, S.T., Lawrence, A.J., 2005. Purinergic modulation of cardiovascular function in the rat locus coeruleus. Br. J. Pharmacol. 145, 342-352. https://doi.org/10.1038/sj.bjp.0706179 


\section{LEGENDS OF FIGURES}

Figure 1. Social behavior in VPA autism model. (A) Time spent in chambers and interaction time in sociability (B), social novelty tests in a threechambered apparatus and $(C)$ number and time of total pro-social interactions. Data expressed as means \pm SEM. Asterisks indicate statistical differences with ${ }^{*} p<0.05,{ }^{* *} p<0.01,{ }^{* *} p<0.001$. Statistical analysis: Generalized Estimating Equations (GEE) followed by Bonferroni. Three-chambered test: CON $(n=15)$, SUR $(n=15)$, VPA $(n=11)$, VPA+SUR $(n=13)$. Reciprocal interactions: CON $(n=18)$, SUR $(n=$ 16), VPA $(n=14), \operatorname{VPA}+\operatorname{SUR}(n=13)$.

Figure 2. Anxiety, exploratory and locomotor behavior in VPA autism model. (A) Percent of time spent in the open arms in the elevated plus-maze; (B) Time spent in central square; (C) Number of rearings and (D) distance travelled in a $50 \times 50 \times 50$ open field arena. Data expressed as means \pm SEM. Different letters indicate statistical differences with $p<0.05$ considered significant. Statistical analysis: Generalized Estimating Equations (GEE) followed by Bonferroni. Plus Maze: CON ( $n$ $=18)$, SUR $(n=16), \operatorname{VPA}(n=15), \operatorname{VPA}+\operatorname{SUR}(n=15)$. Open Field: $\operatorname{CON}(n=16)$, $\operatorname{SUR}(n=15), \operatorname{VPA}(n=13), \operatorname{VPA}+\operatorname{SUR}(n=14)$.

Figure 3. Self-grooming behavior in VPA autism model. Time of (A) complete, (C) incomplete and (E) total grooming; Number of (B) complete, (D) incomplete and $(\boldsymbol{F})$ total grooming. Data expressed as means \pm SEM with ${ }^{* *} p<0.01$ considered significant.. Statistical analysis: Generalized Estimating Equations (GEE) followed by Bonferroni. CON $(n=16)$, SUR $(n=15)$, VPA $(n=13)$, VPA+SUR $(n=14)$.

Figure 4. Sensorial behavior in VPA autism model. (A) Total score in Whisker Nuisance Task and (B) latency to respond to thermal stimuli. Data expressed as means \pm SEM with ${ }^{*} p<0.05$. Statistical analysis: Generalized Estimating Equations (GEE) followed by Bonferroni. WNT: CON $(n=15)$, SUR $(n=14)$, VPA $(n=13)$, VPA+SUR $(n=13)$. Tail flick: CON $(n=17)$, SUR $(n=14)$, VPA $(n=13)$, VPA+SUR $(n=14)$. 
Figure 5. Expression levels of purinergic receptors in medial prefrontal cortex (A) and hippocampus (B) of young rats from VPA autism model. Plots presented as mean \pm SEM with ${ }^{\star} p<0.05,{ }^{* *} p<0.01,{ }^{* \star *} p<0.001$. Statistical analysis: One-Way ANOVA followed by Tukey's test. $n=8$ for all groups in both tissues.

Figure 6. Expression levels of pro-inflammatory cytokines in medial prefrontal cortex (A) and hippocampus (B) of young rats from VPA autism model. Results expressed as means \pm SEM with ${ }^{*} p<0.05$ considered significant. Statistical analysis: One-Way ANOVA followed by Tukey's test. nMPC $=6-8$ and $\mathrm{nHIP}=8$ for all groups.

Figure S1. Evaluation of individual reciprocal social interaction in VPA autism model. Counts and time of (A) nose-to-nose sniffing, (B) anogenital inspection, (C) flank exploration and (D) following. Data expressed as means \pm SEM with * $p<0.05$ considered significant, indicating a SUR per se effect. Statistical analysis:

Generalized Estimating Equations (GEE) followed by Bonferroni. CON $(n=18)$, SUR $(n=16)$, VPA $(n=14)$, VPA+SUR $(n=13)$.

Figure S2. Exploratory and locomotor behavior in VPA autism model. (A) Open arms entries and (B) Number of risk assessments in the elevated plus-maze apparatus; (C) average speed in a $50 \times 50 \times 50 \mathrm{~cm}$ open field arena. Data expressed as means \pm SEM with ${ }^{*} p<0.05$. Statistical analysis: Generalized Estimating Equations (GEE) followed by Bonferroni. Plus Maze: $\operatorname{CON}(n=18)$, SUR $(n=16)$, VPA $(n=15)$, VPA+SUR $(n=15)$. Open Field: CON $(n=16)$, SUR $(n=15)$, VPA ( $=13), \operatorname{VPA}+\operatorname{SUR}(n=14)$. 

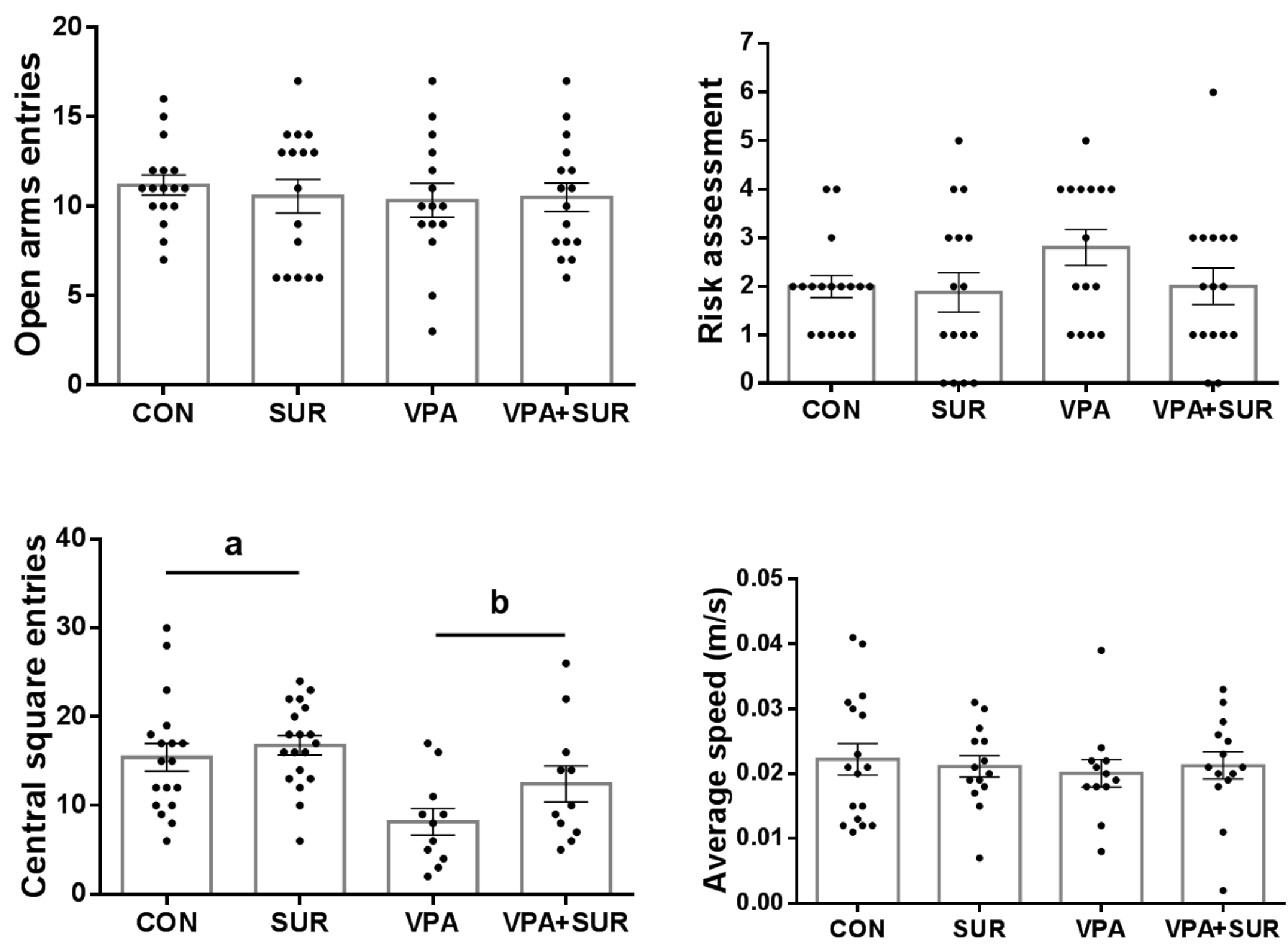
A
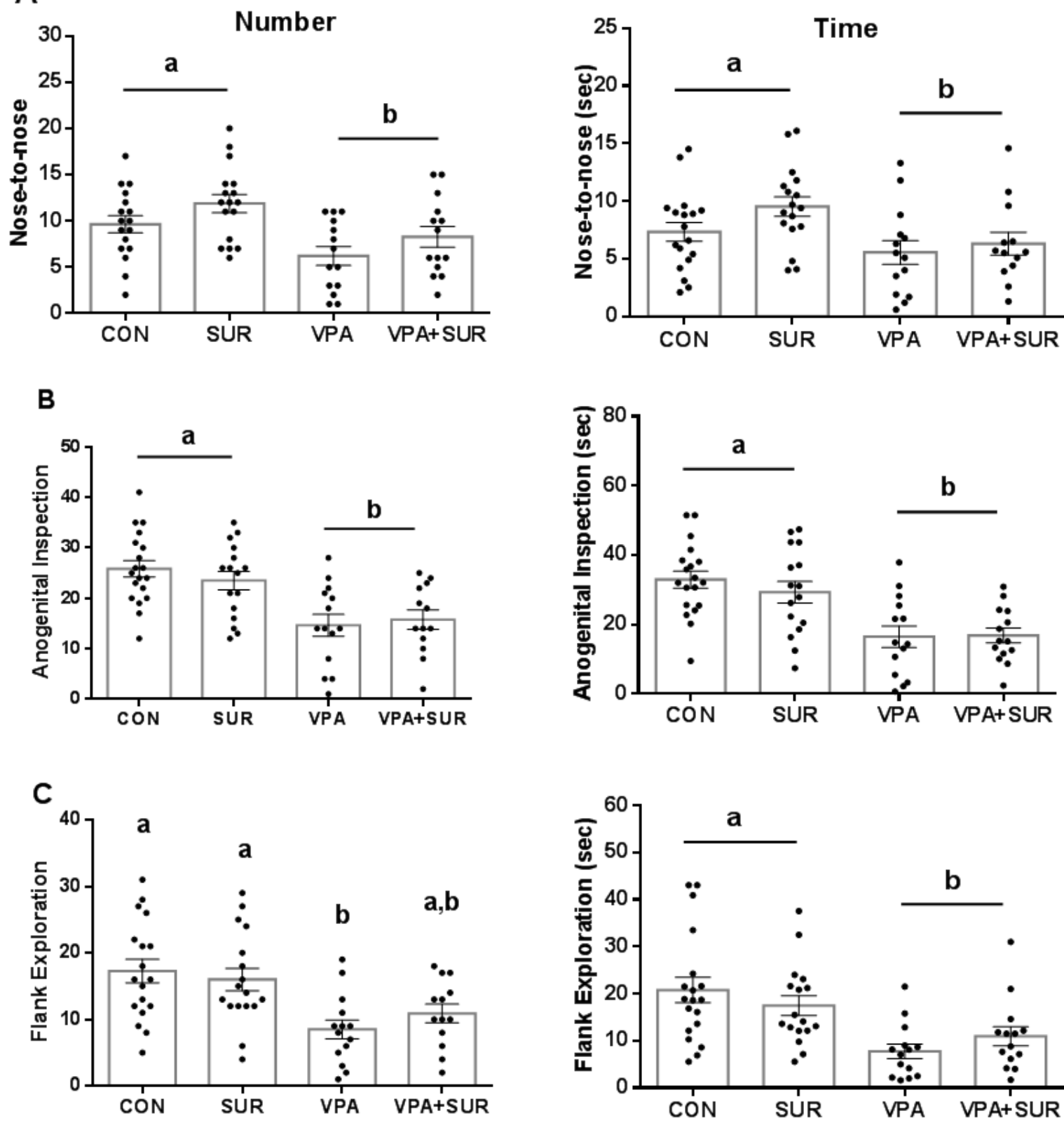

D
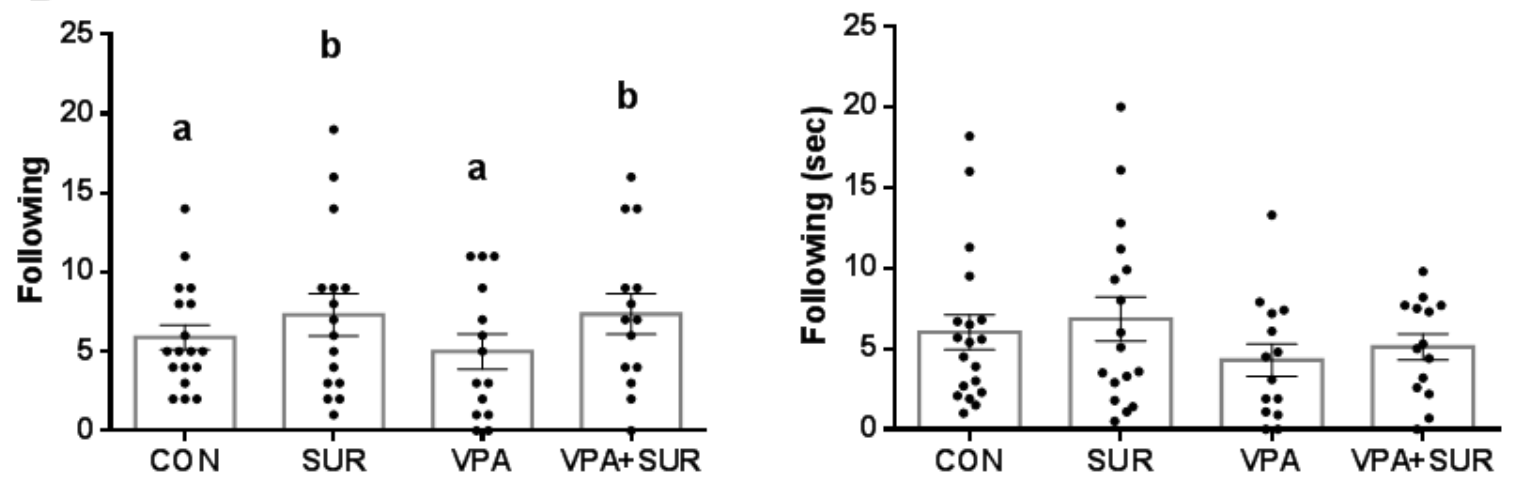
A Medial Prefrontal Cortex
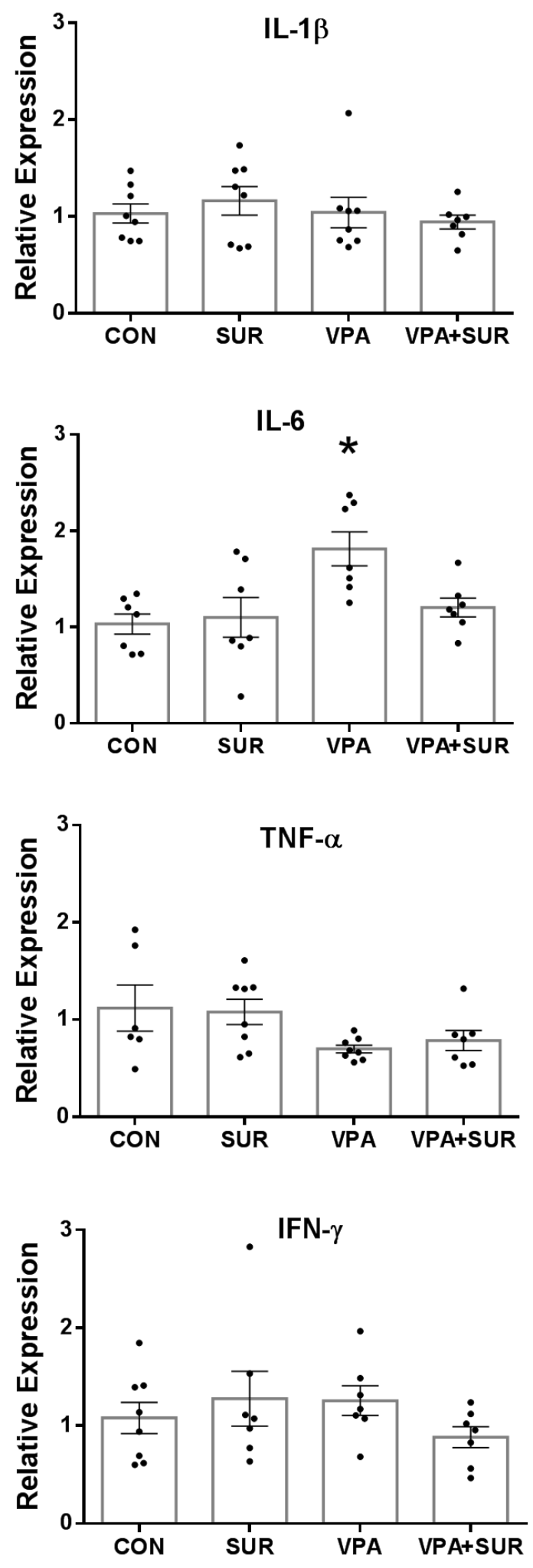

B Hippocampus
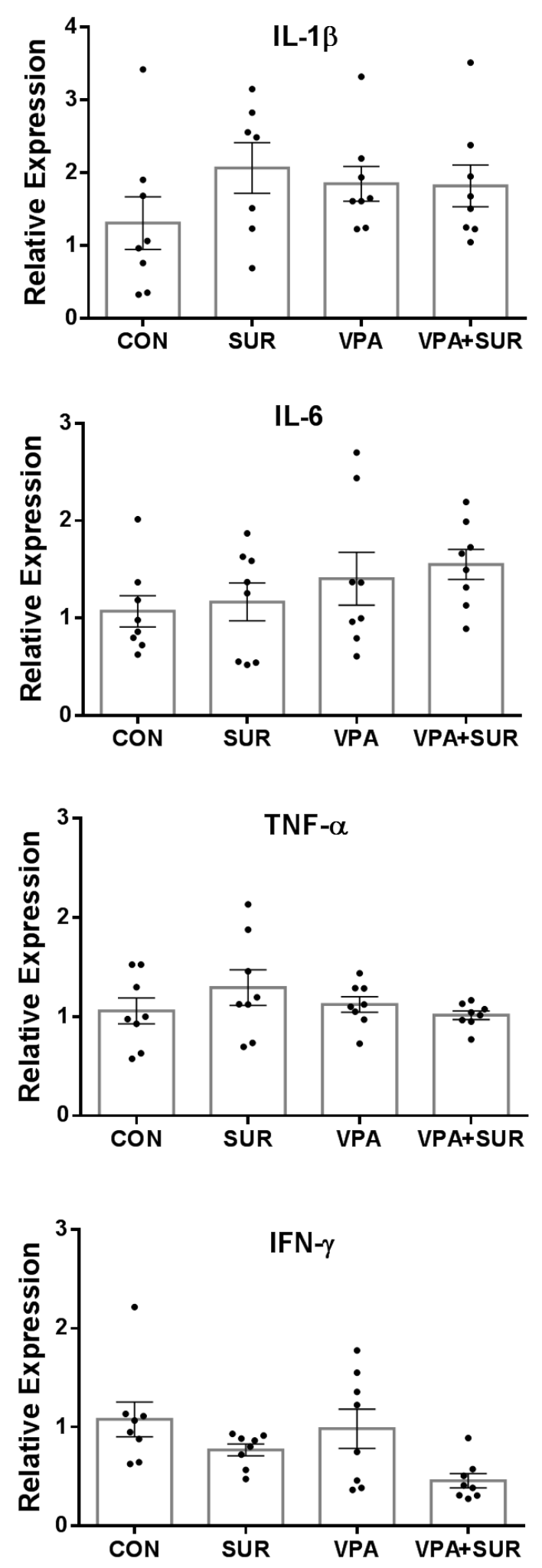
A
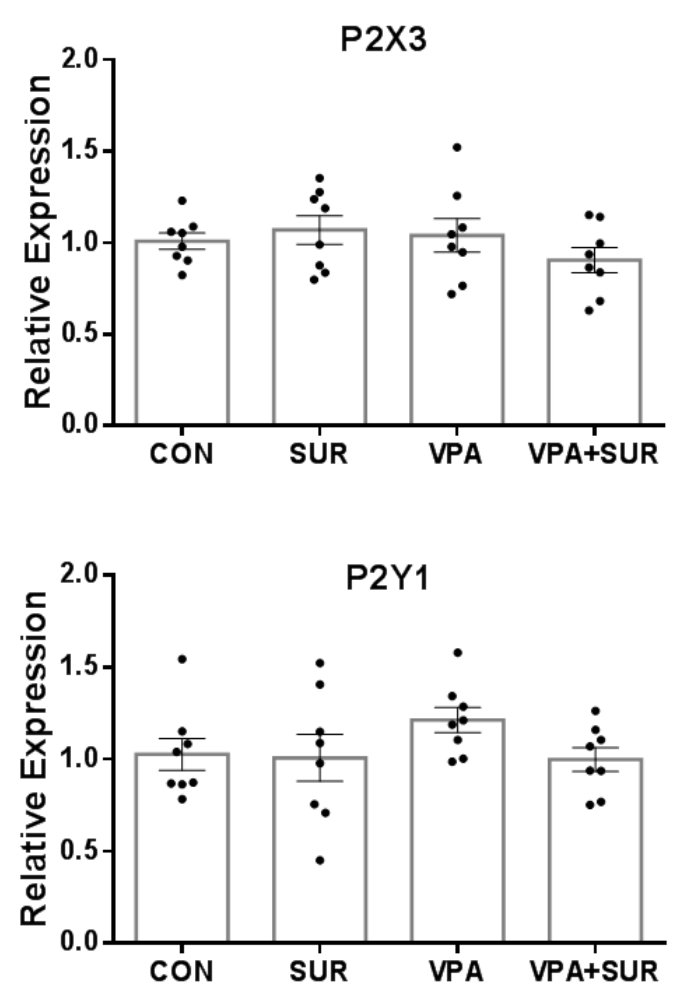

B
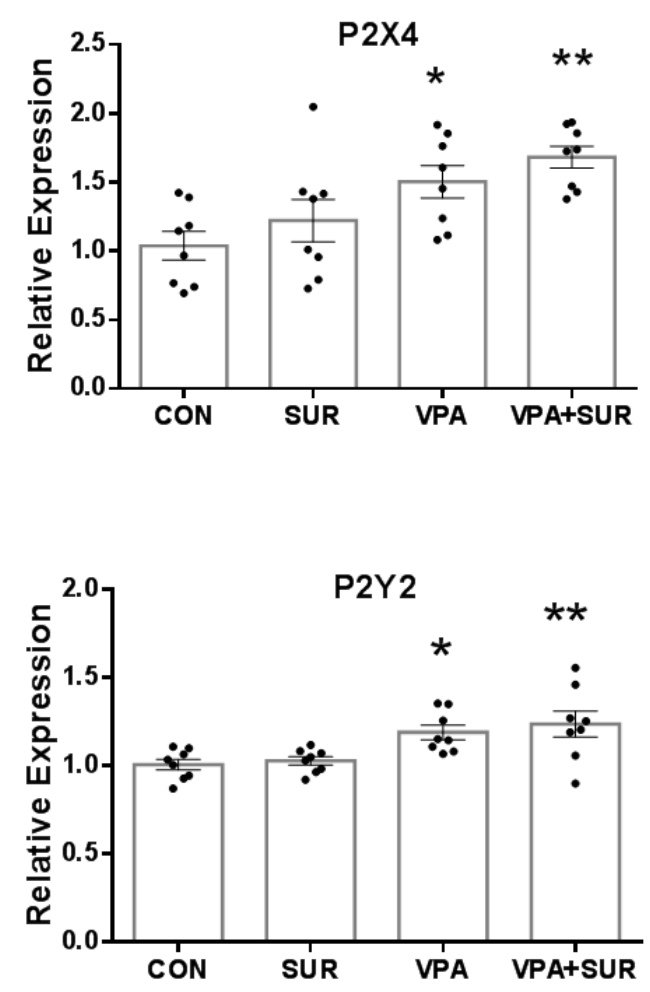

\section{Medial prefrontal cortex}
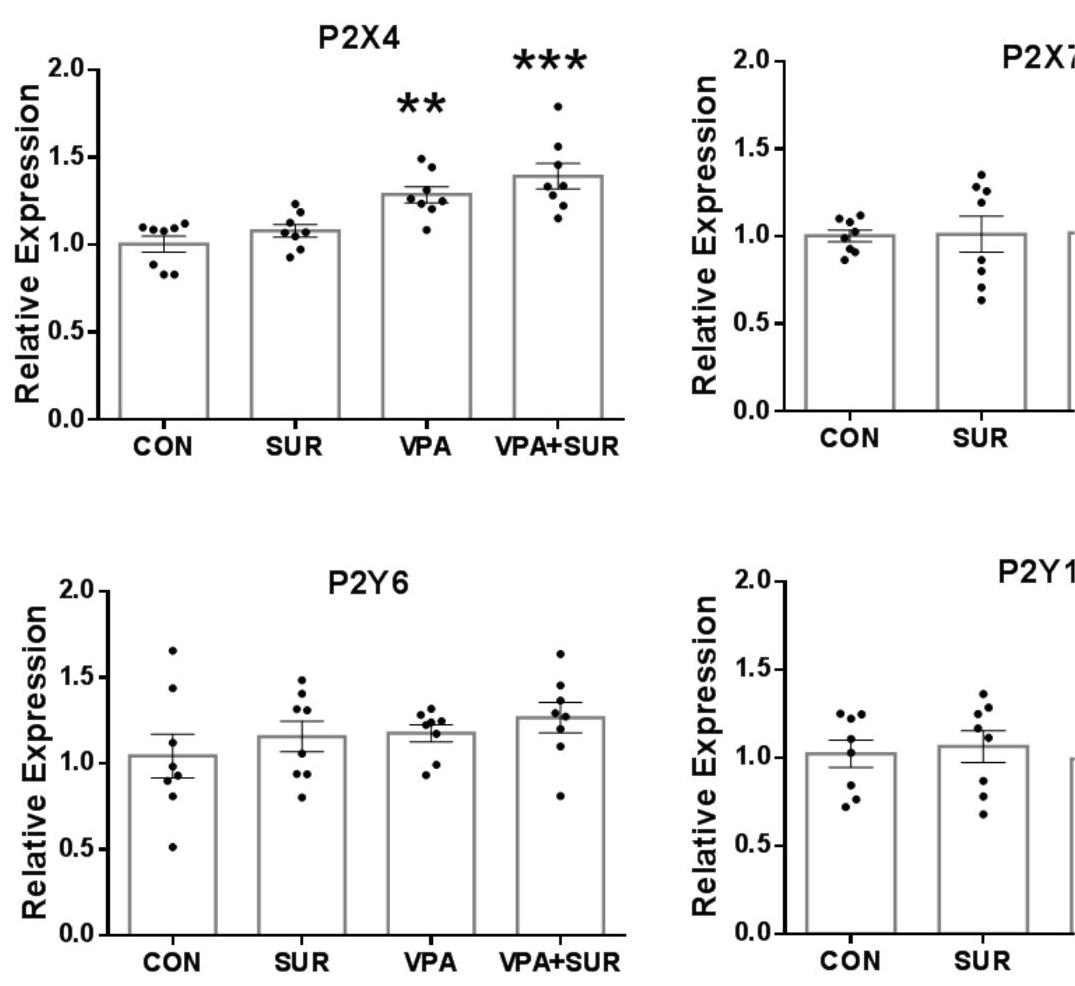

\section{Hippocampus}
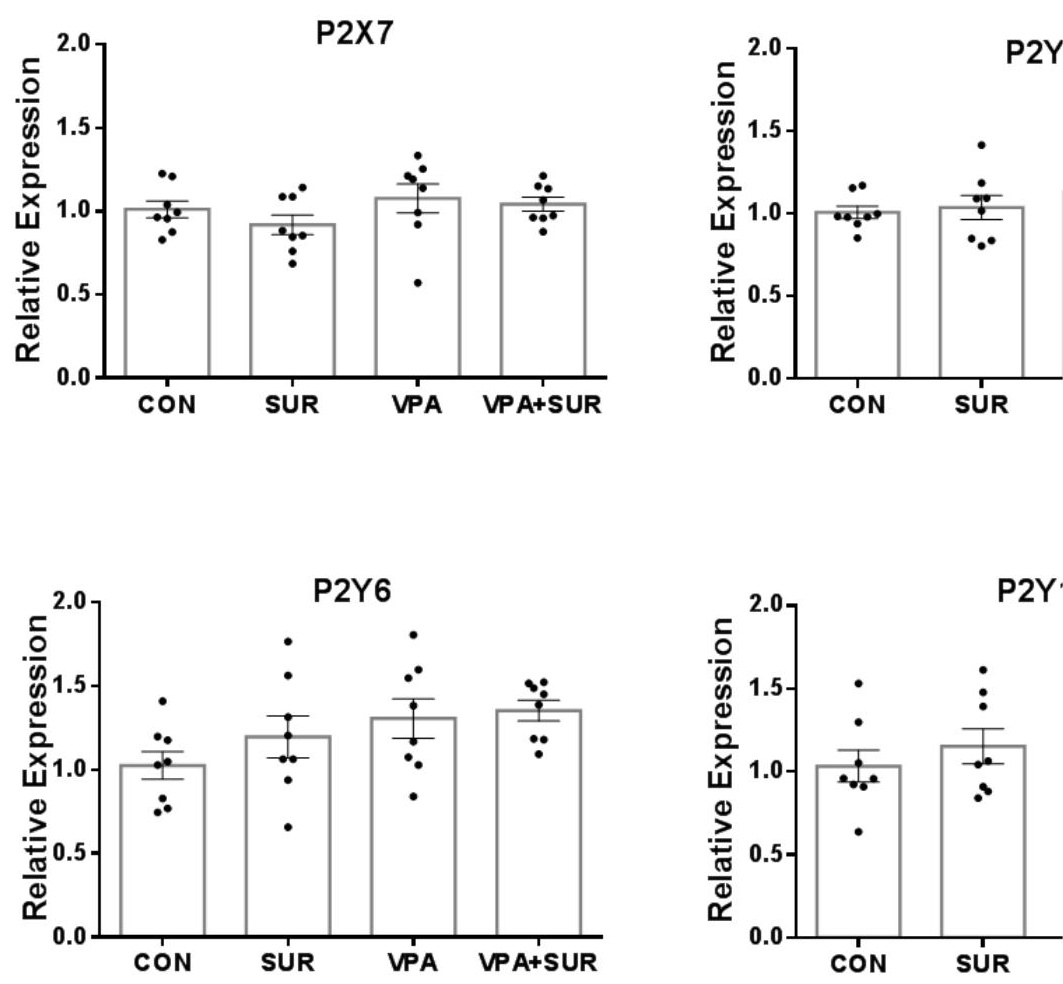

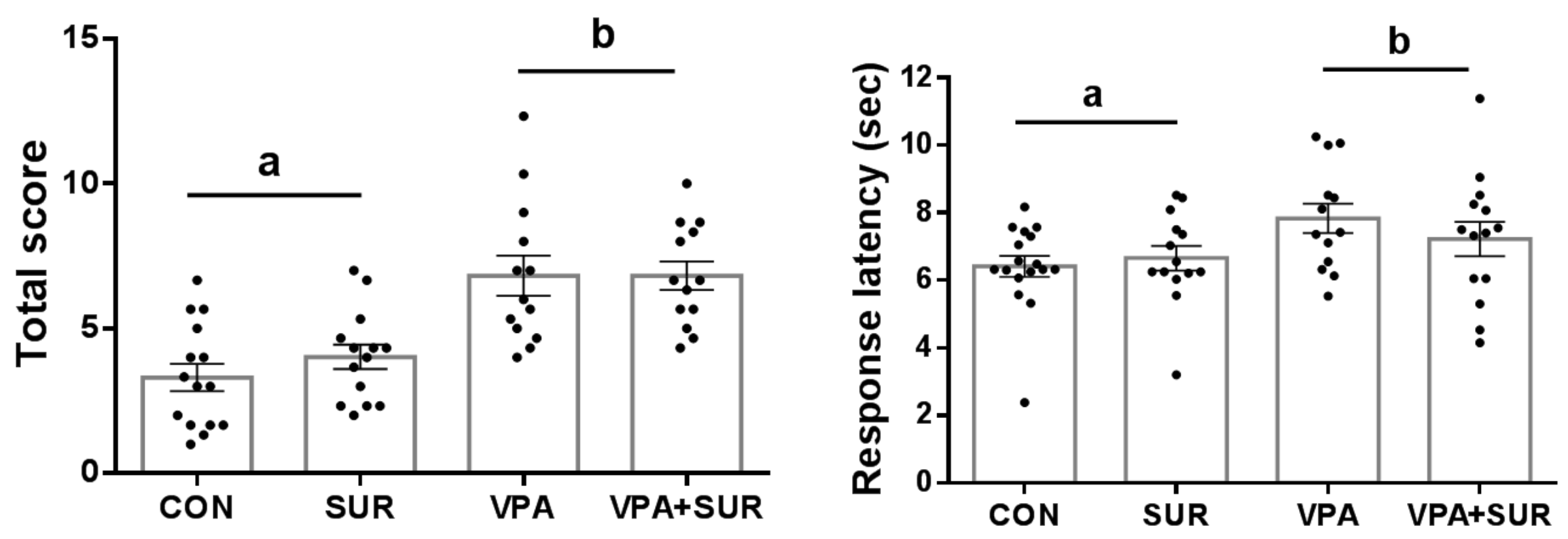

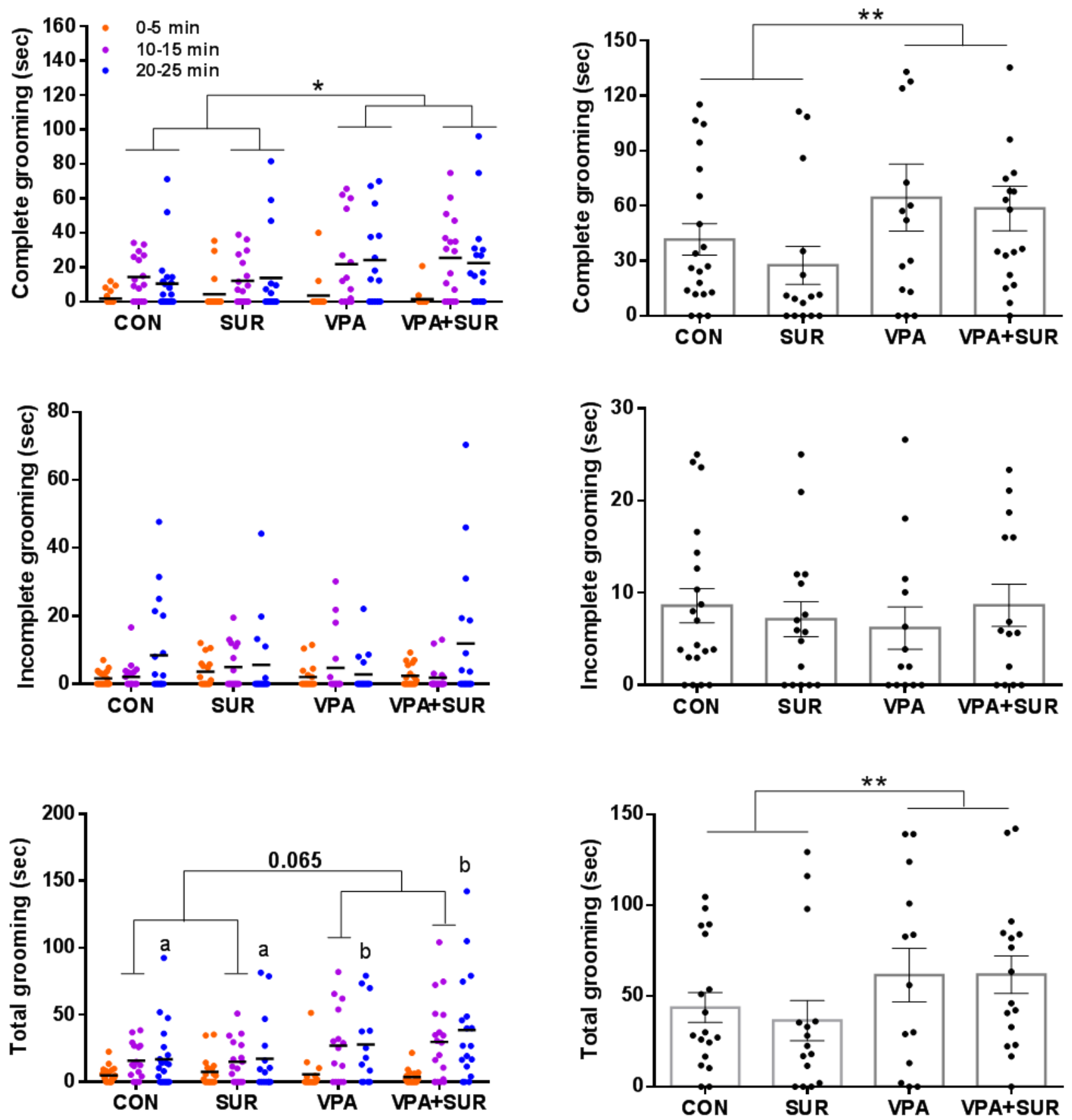

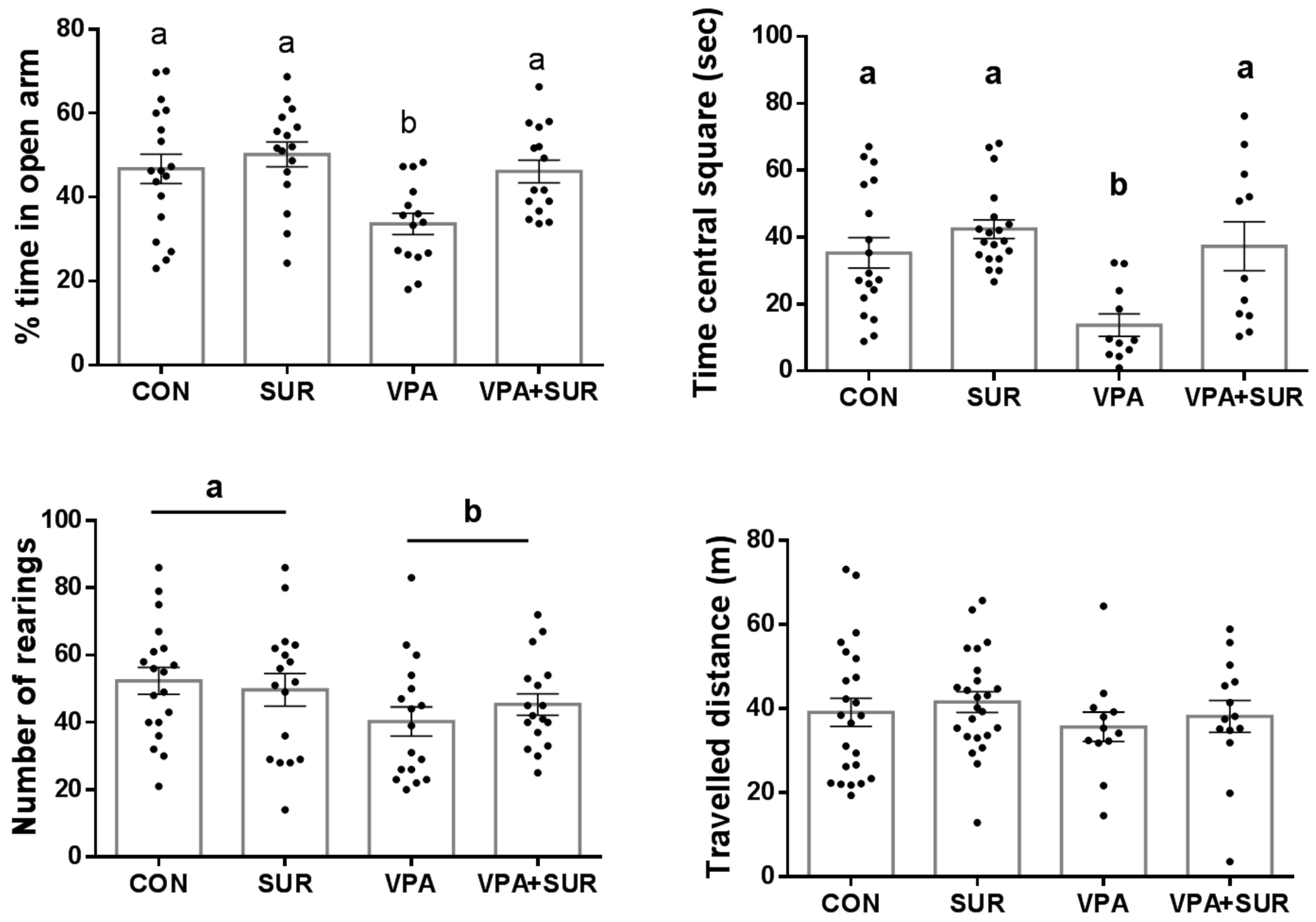

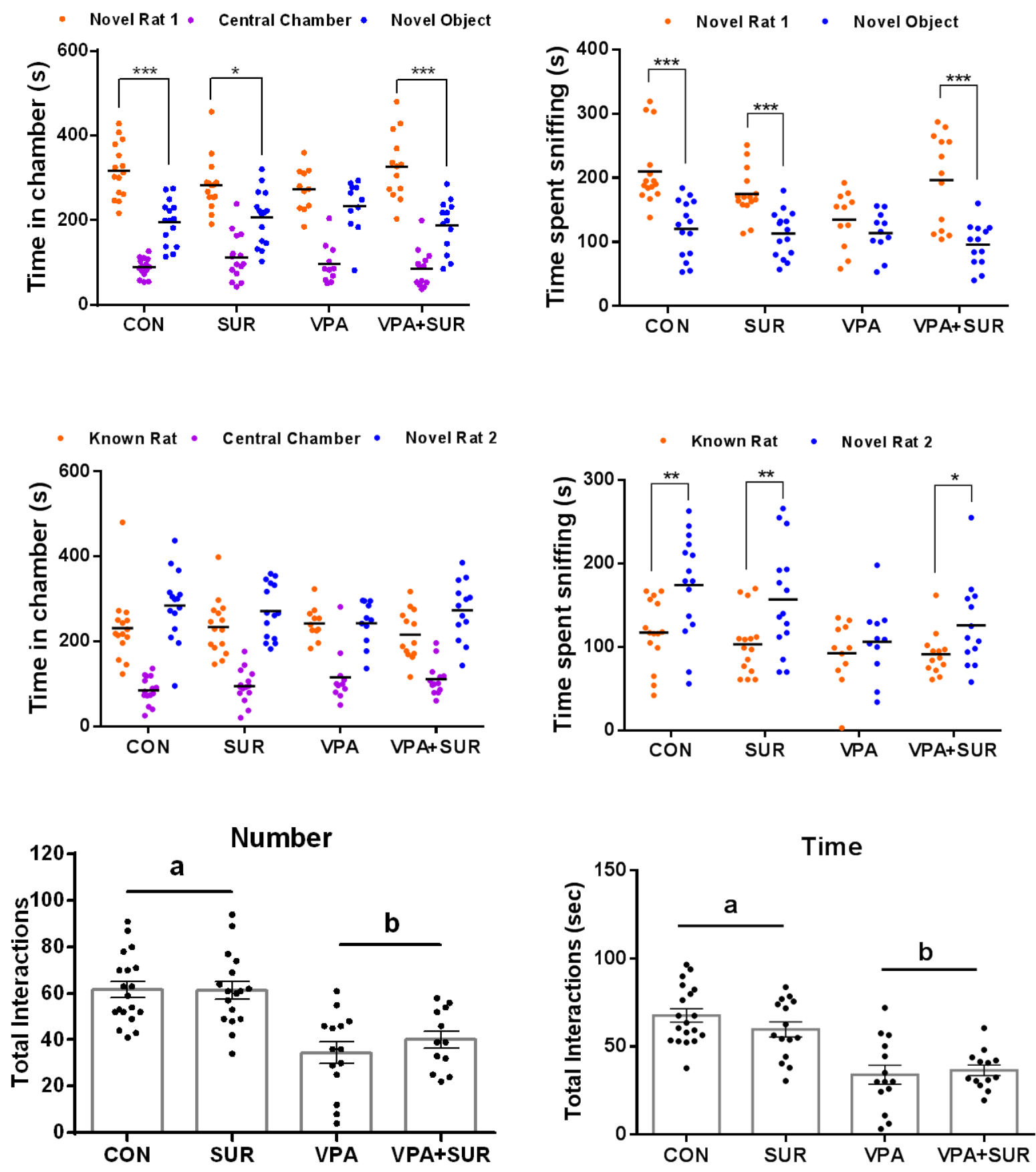

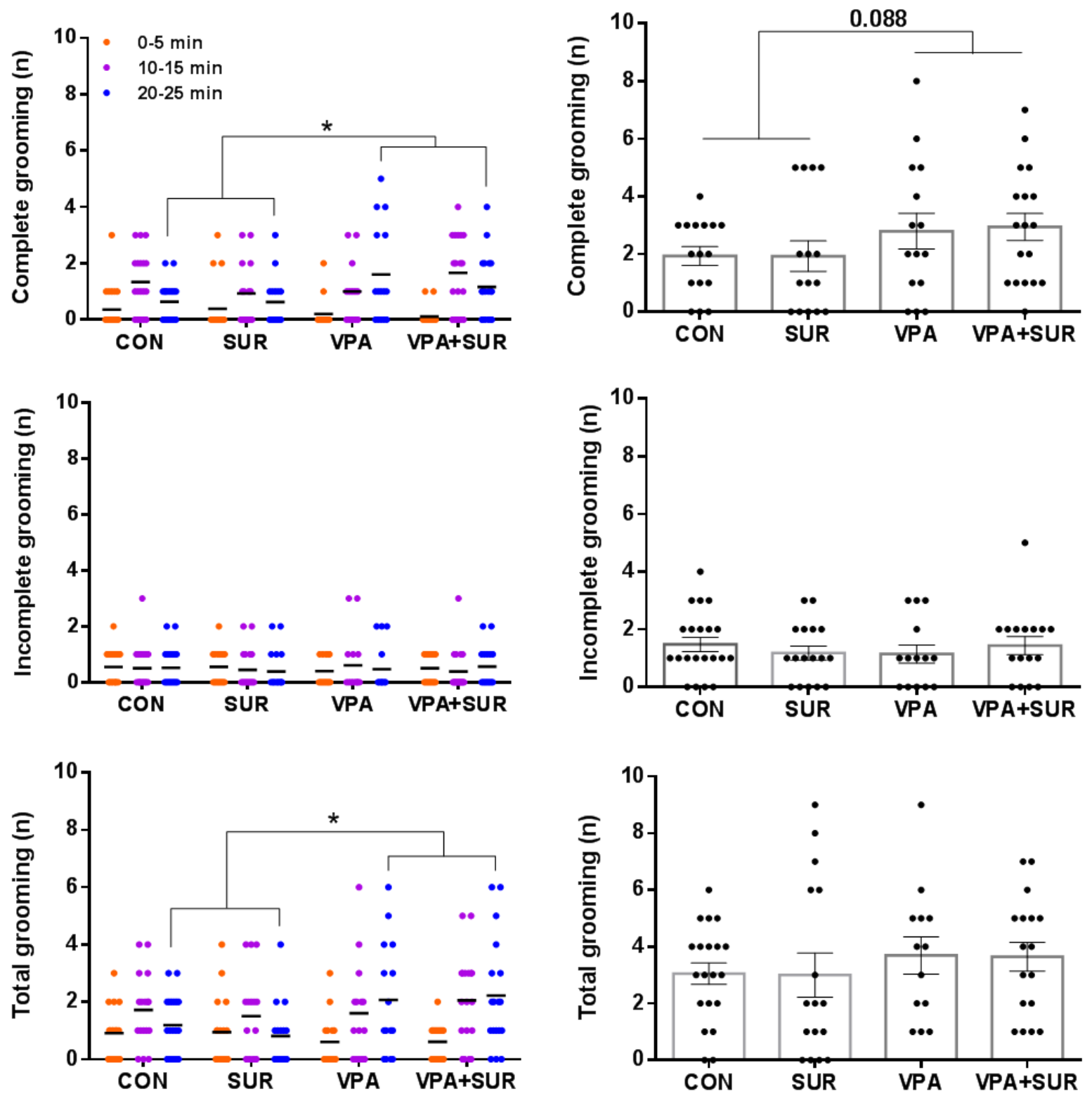